\title{
UN POEMA INÉDITO DEL MAESTRO FRANCISCO DE MEDINA
}

En su Libro de descripción, el pintor Pacheco, suegro de Velázquez, nos ha dejado un breve esbozo del gran humanista sevillano, el Maestro Francisco de Medina'. A la vez nos ofrece un retrato del Maestro, a quien conoció personalmente y con quien estrechó una íntima amistad que duró hasta la muerte de éste, de la que nos da la fecha exacta: el 20 de marzo de I6I5.

Pasó Medina a la posteridad como el autor del célebre prefacio a las Anotaciones de Herrera de las obras de Garcilaso, prólogo elogiado por sus contemporáneos y la crítica moderna como una joya en su género. Por la ejemplar claridad y belleza de su prosa, ha sido comparado con la Défense et Illustration de la langue française de Du Bellay, y don Francisco López Estrada, con gran acierto y razón, lo ha llamado kel Manifiesto" del Renacimiento de los escritores andaluces ${ }^{2}$. Dentro de la llamada Escuela Sevillana, ocupó Medina, después de Herrera, el lugar de más prestigio e influencia, de lo cual nos queda el testimonio de las muchas referencias que el Divino hace a él en las Anotaciones, las propias enmiendas de Medina a los sonetos de Arguijo y los elogios de otros poetas contemporáneos, como Cervantes ${ }^{3}$, Juan de la

1 Libro de descripcion de verdaderos retratos de ilustres $y$ memorables varones. Por Francisco Pachico. En Sevilla, r599. Sin foliar. El retrato de Medina lleva el número 15.

2 Justificación literaria de Pedro Espinosa en Homenaje a Pedro Espinosa Sevilla, I953, p. I2.

- Los rios de eloquencia que del pecho / del grave antiguo Cicerón manaron; / los que al pueblo de Atenas satisfecho / tuvieron, y a Demóstenes honraron; / los ingenios qu'el tiempo ha ya deshecho, / que tanto en los pasados se estimaron, / humillense a la sciencia alta y divina / del maestro Francisco de Medina" (Canto de Caliope, vv. 377-84). 
Cueva ${ }^{1}$, Barahona de Soto ${ }^{2}$, Rodrigo Caro ${ }^{3}$ y Cristóbal de Mesa 4.

No obstante, escribió poco el sabio sevillano. Su buen anigo y devoto discipulo Juan de Robles nos brinda el porqué de este fenómeno entre los hombres de verdadera erudición en su libro El culto sevillano. Iscribe Robles: «Su poca salud fue, según pienso, la que le impidió escribir algo que perpetuase su memorian. Pero añade que sí escribió "cosillas menudas de poesías, que quemó cuando entró a ser Secretario (del Arzobispo dou Rodrigo de Castro) por parecerle que el oficio le obligaba a renunciar de las cosas apacibles y darse todo a las gravesn ${ }^{5}$.

Efectivamente, aparte los versos en los preliminares a la citada obra de Herrera, algunos fragmentos dentro de ella y un trozo recogido en el libro de Baltasar de Vitoria, Teatro de los dioses ", no nos ha llegado nada más.

E1 pintor Pacheco, gracias a quien se han conservado tantas poesfas. de Herrera, logró salvar del holocausto una poesía del Maestro, la que incluyó en una colección manuscrita que lleva por título Poesias varias, año $I 63 x$, y que actualmente se conserva en la Biblioteca de la Universidad de Harvard?. Lleva de rótulo "Del Maestro Francisco de Medinas, cuyo texto integro transcribo a continuación ${ }^{8}$ :

\author{
Alegrane en la noche más sombria \\ $i$ en medio las tivieblas del pecado, \\ ver la lisz divinal del claro dia. \\ Alégrame el semblante lastimrado
}

1 En El Viaje de Sannio, Lib. V., vv. 25-32.

- Epistola de Cristóbal de Mesa a Luis Barahona de Soto (citado por Frarcrsco Rodrfguez Murín, Luis Barahona de Soto, Madrid, I903, p. 468).

- Varones insignes en letras, naturales de la ilustrisima ciudad de Sevilla, Epistolario. Edición de Santiago Monroro. Sevilla, rgr5, p. 35.

- Ingenios españoles y héroes extremeños y andaluces de La restauración. de España, Madrid, I607. En GALIARDO, Ensayo, III, col. 787 .

- Sevilla, r883, p. 3 I.

- Barcelona, 1702, p. 575.

7 El manuscrito, en letras del siglo Xvn, tiene 244 folios $(2 \mathrm{I} \times$ I5,5). Véase su descripción en WIILIAN FICATER, Una poesla contempordnea inédita sobro las bodas do Veldzquez, en Varia Velazqueña. Homenaje a Veldzquez en el III centenario de su muerte, 1660-I960, I, Madrid, I960, p. 636, nota. El poema de Medina aparece en el folio $127 v$.

- Respeto la ortografía antigua, modernizando tan sólo la acentuación y la puntuación. 
5 del viejo que, en su gozo i llano, siente ver llorar a su Dios de frio elado.

Alegrame el exercicio luziente de tanlos cortesanos celestiales que adoran a su Rei alli presents.

ro Alegranme los ojos virginales que están con bellas lágrimas mostrando de sat gozo $i$ dolor claras señales.

Alegrame el infante que, temblando, las fuerfas doma del crusel tirano, I5 $i$ le va de su imperio despojando.

Alegrame ver hecho muestro ermano, quien antes se mostró tan riguroso en vengar nuestras culpas con su mano.

Alegrame ya verle tan piadoso, 20 cusanto lo suele ser un niño tierno sin abrigo al sereno en mes plitvioso, descubierto al rigor del crudo ivierno.

STANKo VRANicL

\section{Leliman College}

City University of New York. 